\title{
Thermodynamic Evaluation of Solar Integration into a Natural Gas Combined Cycle Power Plant
}

\author{
Guangdong Zhu*, Ty Neises, Craig Turchi \\ Concentrating Solar Power Program, National Renewable Energy Laboratory (NREL), Golden, CO 80401 \\ Robin Bedilion \\ the Electric Power Research Institute (EPRI), Palo Alto, California 94304 \\ *Correspondence: guangdong.zhu@nrel.gov
}

\begin{abstract}
The term integrated solar combined-cycle (ISCC) has been used to define the combination of solar thermal energy into a natural gas combined-cycle (NGCC) power plant. Based on a detailed thermodynamic cycle model for a reference ISCC plant, the impact of solar addition is thoroughly evaluated for a wide range of input parameters such as solar thermal input and ambient temperature. It is shown that solar hybridization into an NGCC plant may give rise to a substantial benefit from a thermodynamic point of view. The work here also indicates that a significant solar contribution may be achieved in an ISCC plant, thus implying substantial fuel savings and environmental benefits.
\end{abstract}

Key words: concentrating solar power; integrated solar combined cycle; solar hybridization; thermodynamic analysis

\section{Introduction}

Concentrating solar power (CSP) utilizes mirrors to concentrate sunlight to heat a working fluid and generate electricity by combining the heated working fluid with a thermodynamic power cycle [1]. There exist four main CSP technologies: parabolic trough, linear Fresnel, power tower and dish/engine. CSP is particular friendly to large-scale economic thermal storage which can provide valuable dispatchability to the electric grid. At the same time, a standalone solar thermal power plant with thermal energy storage typically requires intensive capital investment. In an effort to reduce cost, many low-cost CSP collector designs are under development, but lack of operating experience places them at higher investment risk [2]. Consequently, CSP has not yet been adopted as a reliable baseload power deployment, although its installation capacity has been steadily increasing at a rapid pace [3, 4].

One way to deploy CSP with a lower investment risk while retaining power dispatchability, is solar hybridization into fossil-fuel power plants. This approach eliminates a large portion of the capital cost on a partially-operational power block. Additionally, a solar hybridized power plant may greatly reduce the fossil-fuel consumption, thus leading to the reduction of greenhouse-gas emissions and the associated costs. The thermal storage system may also be eliminated or significantly reduced for a solar hybrid plant because the fossil-fuel cycle provides an easy means to smooth power fluctuation under dramatic changes in solar irradiation. Due to these advantages, solar integration into different types of fossil-fuel power plants has been attracting more attention from industries [5]. Depending on the solar heat quality produced by a solar field, solar power may be integrated into a gas turbine, coal-fired Rankine cycle or natural gas combined-cycle (NGCC). A number of solar hybridization projects have been implemented or are under construction across the world $[3,6]$. 
An Integrated Solar Combined-Cycle (ISCC) system adds solar steam produced from a solar field into heat recovery steam generators (HRSG) in an NGCC plant. ISCC can provide significant solar integration allowance into the system [7, 8] and has the potential to achieve substantial economic and environmental benefits, compared with solar integration into other types of power cycles. Previous work has shown that solar-to-electric conversion efficiency may reach around $31 \%$ with a solar contribution of $10 \%$ compared to the overall plant power generation [8]. McMahan and Zervos reported that retrofitting an NGCC through replacing duct burner capacity with solar input can provide economic values when compared to a standalone solar plant [9]. According to Ojo et al. [10], higher solar fractions may be achieved through new ISCC plant design than through retrofitting an existing NGCC plant with solar integration. Montes et al. [11] suggested that solar hybridization may be more beneficial in a hot, dry climate as it provides a natural offset to decreased gas turbine performance on hot days. When retrofitting an existing plant with solar, a thorough feasibility study is needed not only to evaluate the thermodynamic impact of solar integration to the plant, but also to examine realistic physical/operational limitations in the existing plant configuration. A series of reports led by the Electric Power Research Institute (EPRI) [12, 13] showed that, even though a conceptual analysis may suggest a clear benefit from solar hybridization, physical limitations on the solar field size and location and existing power plant equipment limits may add practical constraints to an otherwise feasible solar integration.

In this work, a detailed physical ISCC plant model is used to investigate the thermodynamic impact of solar hybridization into an NGCC plant under design-point and off-design operations for a wide range of important input parameters, such as ambient temperature and solar thermal input. In particular, the paper is organized as follows: first, the ISCC modeling is described; then, the solar injection strategy used to select the solar injection point is elaborated; a thorough parametric study over a wide range of system parameters is presented next to examine the thermodynamic responses of the ISCC system under varying off-design conditions; finally, conclusions and future directions are given.

\section{Modeling of Integrated Solar Combined-Cycle Plant}

An NGCC plant includes gas turbines, steam turbines and HRSGs with an optional duct burner; the design of each may differ with respect to a wide range of design parameters. Furthermore, the performance of each of these components depends on that of the others. Accurate modeling of such a complicated system requires sophisticated modeling tools. Among these, IPSEpro, Thermoflex, GateCycle and Aspen are commercial software often used for power cycle simulations. There also exists some in-house codes that are often limited to a narrow range of NGCC plant operating conditions [14]. IPSEpro is able to provide flexible modeling options for components in an NGCC and is thus adopted as the modeling software here. By using IPSEpro, each component in an NGCC plant can be carefully evaluated at design-point and off-design conditions, which allows detailed thermodynamic modeling of an NGCC plant with solar integration.

\section{a. Natural gas combined-cycle plant}

The NGCC plant used to evaluate solar hybridization potential is illustrated in Figure 1. The plant includes two gas turbines, two HRSGs and one steam turbine. The two gas turbines and two HRSGs are assumed to operate identically and in parallel, so only one set of them are modeled in IPSEpro and the performance of the other set is numerically duplicated in the model. The compressor, combustor and gas turbine are modeled as a whole. The steam turbine includes three pressure stages: high pressure (HP), intermediate pressure (IP) and low pressure (LP). A drycooling system - an air-cooled condenser (ACC) - is used for the steam cycle. The HRSG utilizes the flue gas from the gas turbine to heat the feedwater to the high-pressure, high-temperature steam feeding into the steam turbine, through a series of superheaters, evaporators and economizers. The performance of the NGCC plant and its major components is summarized in Table 1. With the full-capacity duct burner, the overall plant power is boosted from 
1480 MWe to 549 MWe, but the plant efficiency decreases from about 54.9\% to 52\%. The plant efficiency is defined 2 as:

$$
\eta_{\text {plant }}=\frac{W_{\text {net }}}{\dot{m}_{\text {gas }} \cdot L H V_{\text {gas }}}
$$

3 Here, $W_{\text {net }}$ is the net electricity power generation after the deduction of parasitic power loss, $\dot{m}_{g a s}$ is the total mass 4 flow rate of fuel into gas turbines and duct burners, and $L H V_{\text {gas }}$ is the lower heating value of the fuel. 
Table 1: Design parameters of NGCC power plant.

\begin{tabular}{|c|c|c|}
\hline Parameters & Values & Units \\
\hline \multicolumn{3}{|l|}{ Overall Plant } \\
\hline Nominal Ambient Pressure & 0.96 & bar \\
\hline Nominal Ambient Temperature & 20 & ${ }^{\circ} \mathrm{C}$ \\
\hline Gas Turbine & 2 & - \\
\hline HRSG & 2 & - \\
\hline Steam Turbine & 1 & - \\
\hline Duct Burner & Yes & - \\
\hline Cooling & Dry & - \\
\hline Total Capacity - With Duct Burner & 549 & MWe \\
\hline Total Capacity - Without Duct Burner & 480 & MWe \\
\hline Overall Efficiency - with Duct Burner & 0.52 & - \\
\hline \multicolumn{3}{|l|}{ Gas Turbine } \\
\hline Nominal Power Output & 155 & MWe \\
\hline Nominal Efficiency & 0.358 & - \\
\hline Outlet Temperature & 608.3 & ${ }^{\circ} \mathrm{C}$ \\
\hline Pressure Ratio & 17 & - \\
\hline \multicolumn{3}{|l|}{ Steam Turbine } \\
\hline Nominal Power Output & 239 & MWe \\
\hline Nominal Cycle Efficiency & 0.358 & - \\
\hline HP Steam Turbine Isentropic Efficiency & 0.84 & - \\
\hline IP Steam Turbine Isentropic Efficiency & 0.92 & - \\
\hline LP Steam Turbine Isentropic Efficiency & 0.87 & - \\
\hline HP Steam Mass Flow rate & 159.3 & $\mathrm{~kg} / \mathrm{s}$ \\
\hline HP Inlet Temperature & 558.1 & ${ }^{\circ} \mathrm{C}$ \\
\hline HP Inlet Pressure & 98.6 & bar \\
\hline IP Steam Mass Flow rate & 167.6 & $\mathrm{~kg} / \mathrm{s}$ \\
\hline IP Inlet Temperature & 544.7 & ${ }^{\circ} \mathrm{C}$ \\
\hline IP Inlet Pressure & 29.12 & bar \\
\hline LP Steam Mass Flow rate & 182.6 & $\mathrm{~kg} / \mathrm{s}$ \\
\hline LP Inlet Temperature & 310.23 & ${ }^{\circ} \mathrm{C}$ \\
\hline LP Inlet Pressure & 4.964 & bar \\
\hline LP Outlet Temperature & 42.1 & ${ }^{\circ} \mathrm{C}$ \\
\hline LP Outlet Pressure & 0.082 & bar \\
\hline Feedwater Pump Isentropic Efficiency & 0.7 & - \\
\hline $\begin{array}{r}\text { HP Feedwater Pressure } \\
\end{array}$ & 110.1 & bar \\
\hline \multicolumn{3}{|l|}{ HRSG } \\
\hline Flue Gas Inlet Temperature & 608.3 & ${ }^{\circ} \mathrm{C}$ \\
\hline Flue Gas Outlet Temperature & 72.9 & ${ }^{\circ} \mathrm{C}$ \\
\hline No. of HP Exchangers & 5 & - \\
\hline No. of IP Exchangers & 5 & - \\
\hline No. of LP Exchangers & 3 & - \\
\hline
\end{tabular}




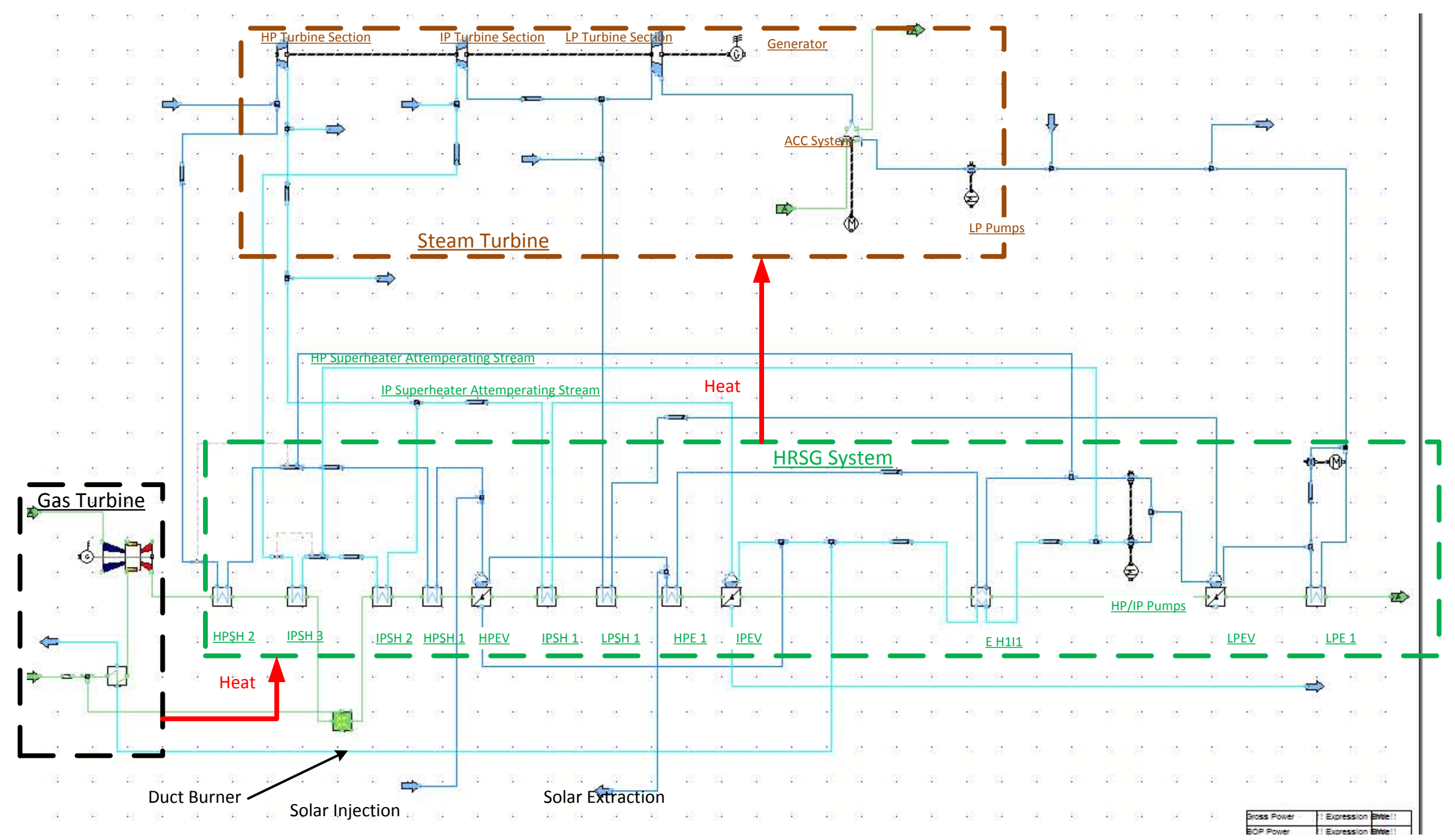

Figure 1: Screenshot of the ISCC plant configuration in IPSEpro. HP stands for high pressure; IP stands for intermediate pressure; LP stands for low pressure; SH stands for superheater; EV stands for evaporator; E stands for economizer. The Economizer E_H1I1 is the dual heat exchanger for both high-pressure water and intermediate-pressure water. 


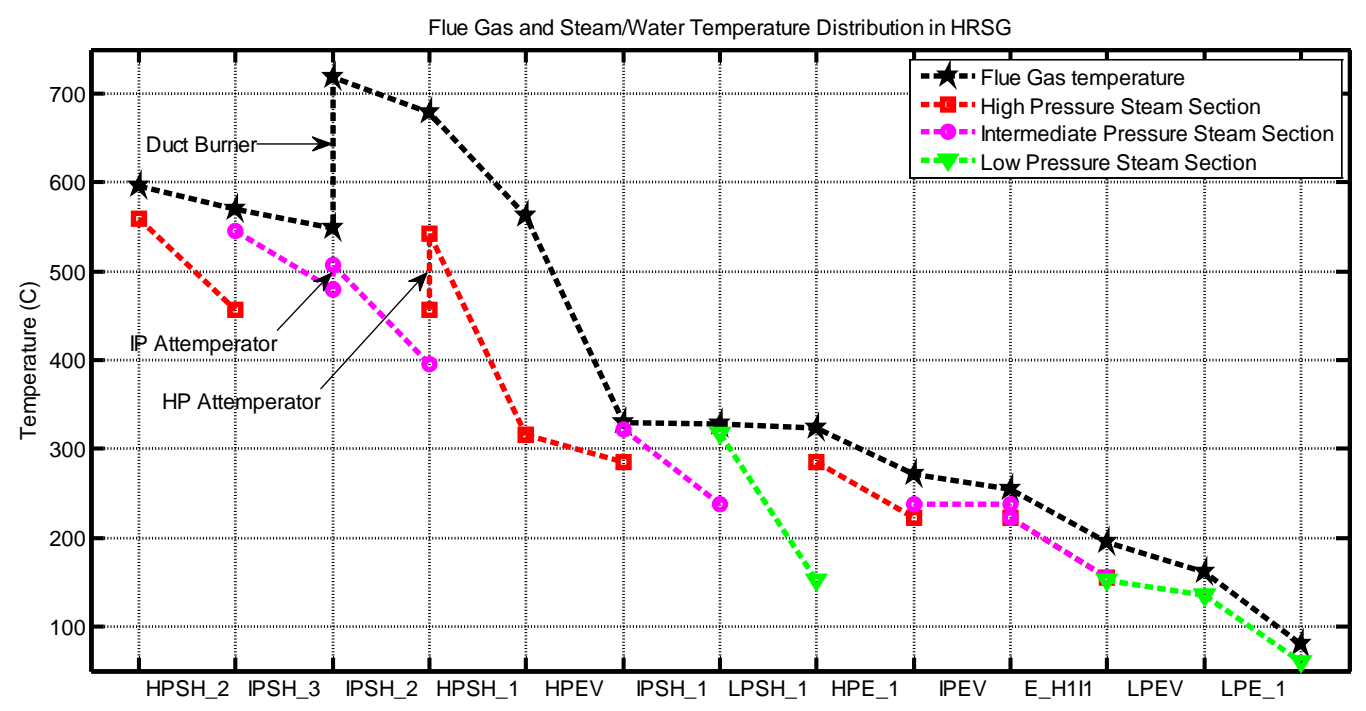

Figure 2: Flue gas and steam/water temperature distribution in an HRSG at design conditions: an ambient temperature of $20^{\circ} \mathrm{C}$, an ambient pressure of 0.96 bar, duct burning, and no solar thermal input.

In Figure 2, the temperature distribution of steam/water and flue gas in the HRSG is plotted against the series of heat exchangers, following the flue gas pathway from high temperature to low temperature. The two ends of each line segment indicate the inlet and outlet temperatures of one heat exchanger. The HRSG system includes five HP heat exchangers, five IP heat exchangers and three LP heat exchangers. Please note that there exists a dual-pressure economizer (E_H1I1, marked in Figure 1 and Figure 2) for HP and IP feedwater heating. The impact of the duct burner to the flue gas temperature and the effects of the HP and IP attemperators can also be recognized in the plot.

\section{b. $\quad$ Off-design plant behavior}

The performance of a gas turbine largely depends on ambient conditions. As shown in Figure 3, the gas turbine cycle efficiency is plotted as a function of ambient temperature at a plant elevation of about $425 \mathrm{~m}$ (0.96 bar ambient pressure). It drops from about 0.365 at the ambient temperature of $0{ }^{\circ} \mathrm{C}$ to 0.346 at $35^{\circ} \mathrm{C}$. Because the gas turbine cycle efficiency is largely determined by the ambient temperature and the pressure ratio, it is typically insensitive to the ambient pressure [15]. In Figure 4, the power output of the reference gas turbine is plotted as a function of ambient temperature for varying ambient pressure. With increasing ambient temperature, the mass flow rate entering into the compressor and the gas turbine will reduce, thus resulting in decreasing power output. For example, when the ambient temperature changes from $0{ }^{\circ} \mathrm{C}$ to $35^{\circ} \mathrm{C}$ at an ambient pressure of $0.96 \mathrm{bar}$, the power output decreases from $171 \mathrm{MWe}$ to $140 \mathrm{MWe}$, which is about $18 \%$ reduction. If the ambient pressure decreases, the results are similar.

Because the power output of the gas turbine is particularly sensitive to the ambient conditions, the mass flow rate of exhaust flue gas heat into the HRSG will vary under varying ambient conditions and thus the steam turbine load will be greatly affected as well. Due to the fact that ambient temperature varies during a day, the NGCC plant basically runs at off-design points most of the time throughout a year. During the course of a year, the duct burner load may also vary depending on the need to fulfill the power demand from the grid operator, thus making the plant run at offdesign conditions as well.

When an NGCC plant is integrated with solar power, the plant performance changes with the variation of solar power input resulting from the varying solar irradiation. Especially when the solar fraction is fairly significant, the 
1 plant performance may deviate greatly from its fossil-only state. Thus for an NGCC plant hybridized with solar, it is 2 particularly important to accurately capture a wide range of the plant off-design operating conditions.

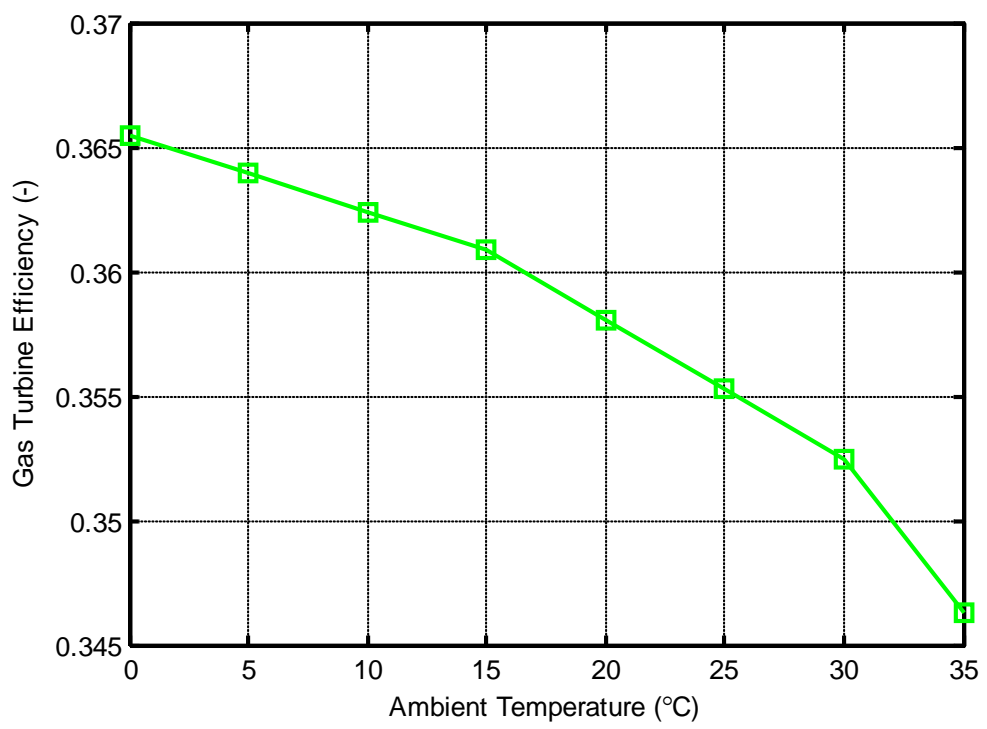

Figure 3: Gas turbine efficiency as a function of ambient temperature at a plant elevation of $425 \mathrm{~m}$.

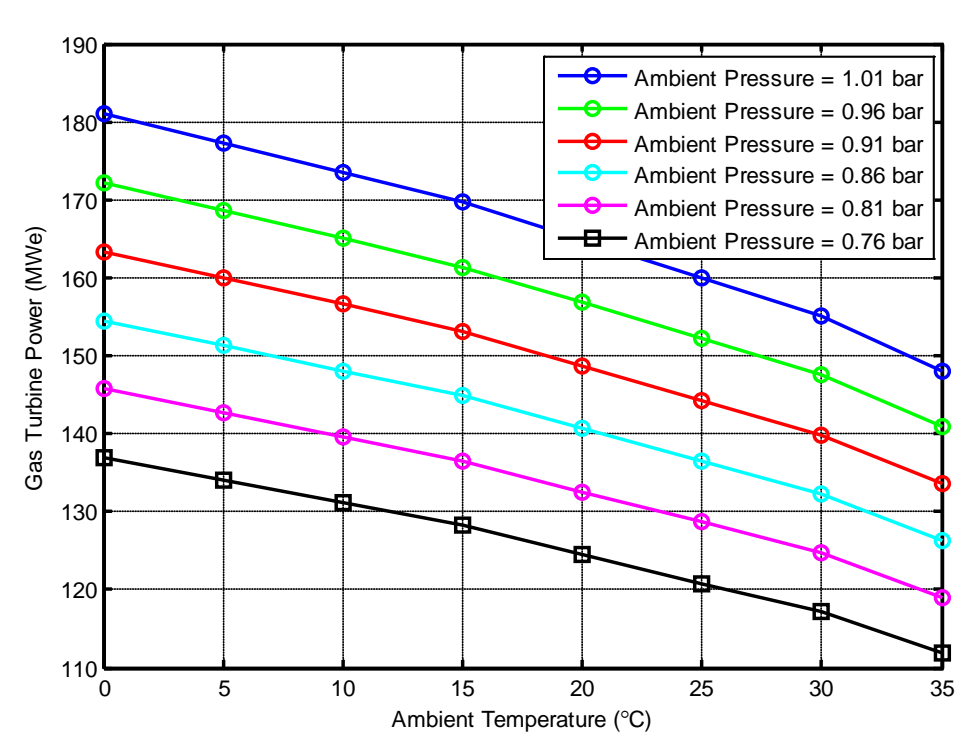

Figure 4: Gas turbine power as a function of ambient temperature for varying ambient pressure.

$+2$

7

\section{III. Solar Injection Strategy}

When an NGCC plant is integrated with solar through an HRSG, a certain amount of feed water or steam will be extracted from the HRSG, heated by the solar energy from the solar field and routed back to the HRSG. When solar collectors can directly accept water/steam, the feed water or steam from the NGCC can be heated directly in the solar field; when a heat transfer fluid (HTF) different from water/steam is running in the solar collectors, a heat 
exchanger will be added between the hot HTF from the solar field and the feed water/steam from the NGCC plant [16].

The solar injection point is a critical parameter. Generally speaking, a higher solar injection pressure/temperature leads to a higher solar conversion efficiency. Here, solar conversion efficiency is defined as:

$$
\eta_{\text {solar }}=\frac{W_{\text {solar }}}{Q_{\text {solar }}}=\frac{W_{\text {fossil }+ \text { solar }}-W_{\text {fossil }}}{Q_{\text {solar }}}
$$

Here, $W_{\text {solar }}$ is the electricity power output generated from the solar heat, $W_{\text {fossil }}$ is the plant electricity power output when the ISCC plant is not using solar power and $W_{\text {fossil }+ \text { solar }}$ is the plant electricity power output when the ISCC plant uses solar power from the solar field. $Q_{\text {solar }}$ is the total heat absorbed from the solar field.

Secondly, solar integration into a NGCC plant often requires non-trivial system modifications in many cases, thus it may be preferable to maximize solar fraction in an ISCC plant design. Solar fraction is defined as the ratio of electricity generation boosted by solar heat compared with the overall electricity generation:

$$
F_{\text {solar }}=\frac{W_{\text {solar }}}{W_{\text {fossil }+ \text { solar }}}
$$

Solar heat is typically used to complement or replace part of the heat supply of one or more heat exchangers in the HRSG. In this scenario, the size of the relevant heat exchanger(s) needs to be relatively large in order to achieve a high solar fraction. Figure 5 shows the exchanged heat for each heat exchanger in the HRSG. As seen in the figure, the HP superheater 1 (HPSH1), HP evaporator (HPE) and IP superheater 2 (IPSH2) are the three largest heat exchangers in the HRSG and would be potential choices to reach a high solar fraction.

Lastly, it is assumed that feed water (not steam) is extracted from the HRSG. It is easier to handle the water at its liquid state than the steam at its gaseous state in the solar collectors, and this also allows large solar input due to evaporation and the possible use of direct steam generation solar collectors.

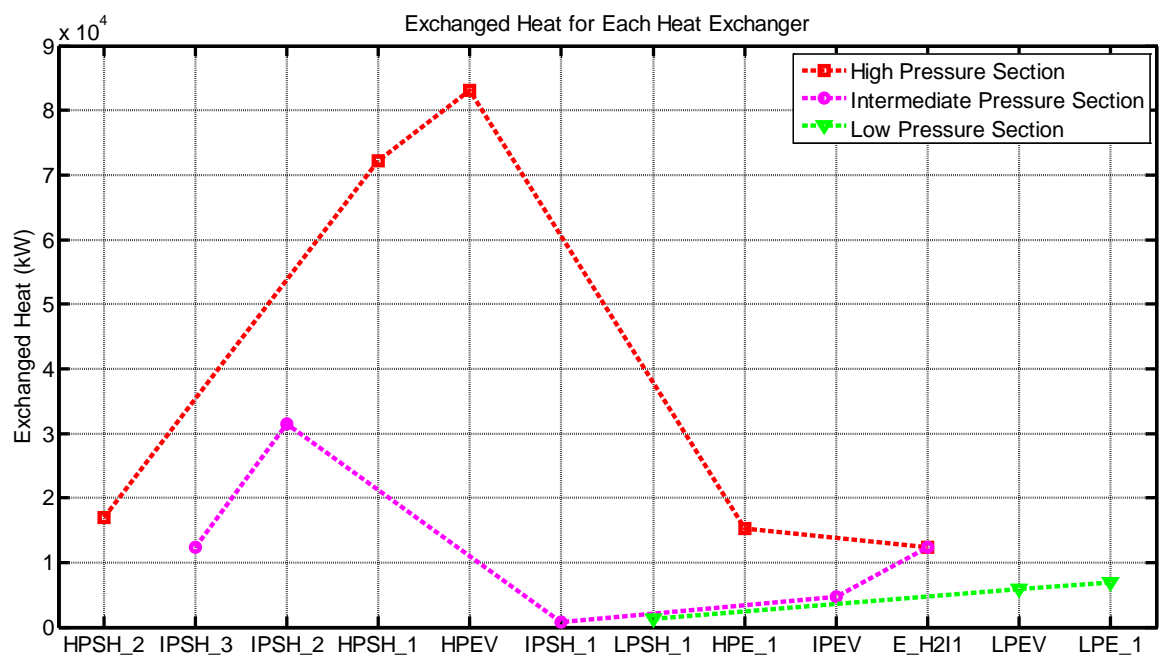

Figure 5: Heat exchange distribution of heat exchangers in HRSG.

Combining the solar injection principles above, one may naturally conclude that a solar injection point into the outlet of the HP evaporator would be a reasonable choice for the reference ISCC plant. As shown in Figure 1, the feed water is extracted at the inlet of the HP evaporator and sent to the solar field. After heated, the evaporated 
steam is injected into the outlet of the HP evaporator. This particular solar injection strategy results in the following benefits:

- The solar field basically serves as an evaporator so that, for a direct steam generation (DSG) solar field, most solar collectors carry feed water, thus minimizing the portion of solar collectors carrying steam.

\section{IV. Parametric Study}

The ISCC model allows one to evaluate off-design conditions under a wide range of input parameters, such as solar thermal input and ambient temperature. When solar heat is integrated into the system, the duct burner is turned off to provide the capacity room in the steam turbine.

\section{a. Effect of solar heat variation}

The amount of solar heat into the ISCC mainly depends on the direct normal irradiance (DNI) of the sun. Over the course of a day, the DNI varies and solar heat will change accordingly. When solar heat is added into the ISCC, the total amount of steam generated by the HRSG increases. The increase in steam generation will have an extensive impact on the HRSG and the steam turbine.

Figure 6 gives the HP turbine inlet steam pressure and temperature as a function of solar thermal input at an ambient temperature of $20^{\circ} \mathrm{C}$ and a plant elevation of 425 meters. The corresponding ambient pressure is about 0.96 bar. With increasing solar heat, the HP turbine pressure increases steadily. When the solar thermal input reaches 160 MW-th, the HP steam pressure is brought to the design point pressure of about 100 bar. This indicates that the steam turbine adopts a sliding-pressure operation at partial loads. In contrast, the HP turbine inlet temperature is controlled to stay roughly constant at first for a relatively small amount of solar heat and starts to drop with increasing solar heat. This is because the heat from the flue gas is fixed and it cannot provide enough superheat to bring the steam to the design value with increasing mass flow rate of HP steam resulting from added solar heat in the HRSG. 


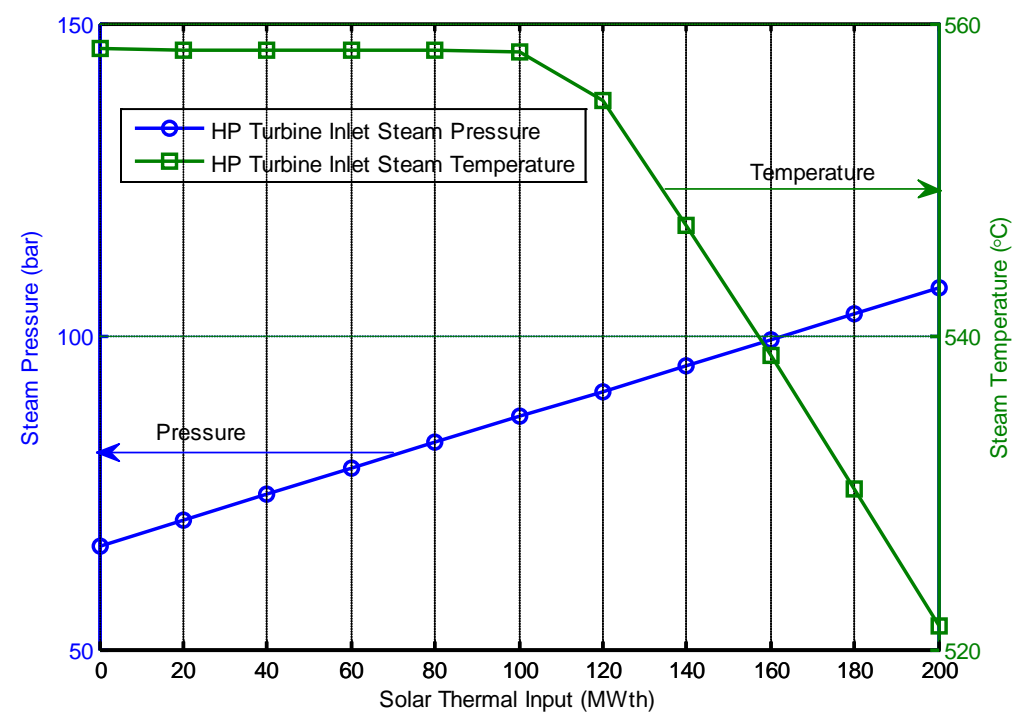

Figure 6: Steam condition at HP turbine inlet as a function of solar thermal input at an ambient temperature of $20{ }^{\circ} \mathrm{C}$ and a plant elevation of 425 meters.

$4 \quad$ In Figure 7, the solar steam injection pressure and temperature are also plotted as a function of solar thermal input. Due to the increasing HP turbine inlet steam pressure with increasing solar heat, the steam/water pressure in all heat exchangers increases. In particular, for the HP evaporator where solar heat is injected, its injection pressure and temperature increases, as shown in the figure. The solar steam injection point temperature increases from about 305 ${ }^{\circ} \mathrm{C}$ to $344^{\circ} \mathrm{C}$ when the solar heat increases from zero to about $200 \mathrm{MWth}$. The solar steam temperature is set to be $20^{\circ} \mathrm{C}$ higher than the injection point in order to maintain the dry steam condition at the inlet of the first HP

10 superheater.

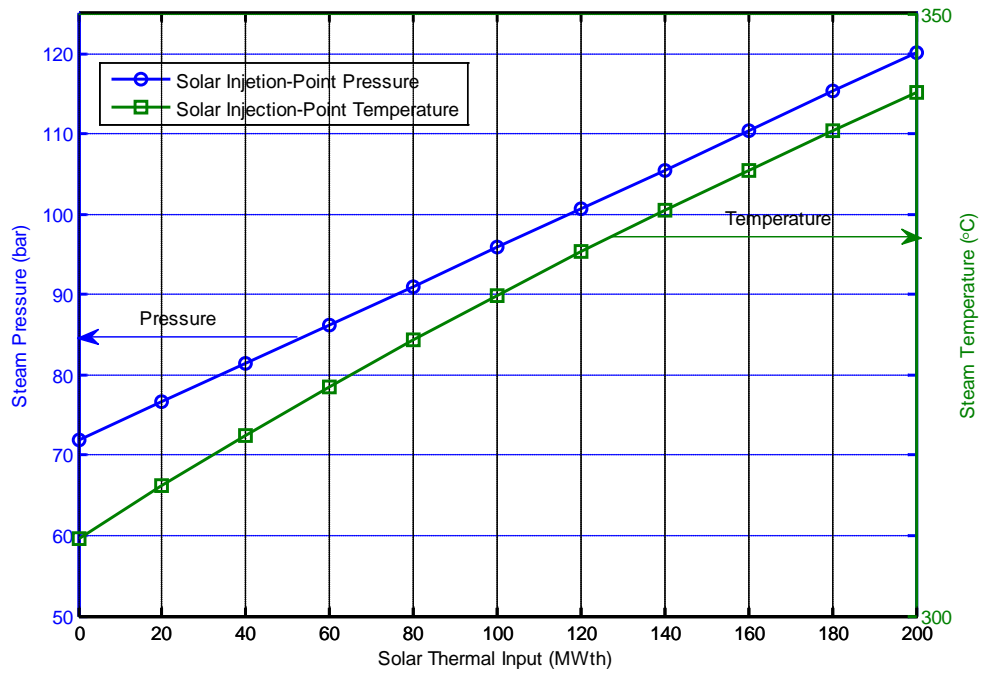

Figure 7: Steam condition at solar injection point as a function of solar thermal input at an ambient temperature of $20^{\circ} \mathrm{C}$ and a plant elevation of 425 meters.

Solar conversion efficiency is calculated and plotted along with the steam cycle efficiency as a function of solar thermal input in Figure 8. It can be seen that the solar conversion efficiency is noticeably higher than the steam cycle 
1 efficiency. As seen in equation (2), solar conversion efficiency is defined as the ratio of the plant output power 2 boosted by the solar addition to the solar heat input. The boosted power includes the power generated from the 3 added solar heat and the additional power extracted from the fossil heat due to the increasing steam cycle efficiency 4 as a result of solar addition. As shown in Figure 8(a), when solar thermal input increases, the steam cycle efficiency 5 increases because the steam turbine load increases and approaches the full load with the absence of duct burner 6 firing. As mentioned earlier, to reserve enough capacity room in the steam turbine to accept the additional solar heat, 7 the duct burner was turned off in the HRSG. The increase of the steam cycle efficiency leads to additional power 8 generated out of the fossil heat, which is also counted as part of the power boosted by the solar addition.

9 In addition, Figure 8(a) indicates that the solar conversion efficiency decreases with increasing solar thermal input. 10 This is due to the fact that the corresponding steam cycle efficiency follows an asymptotic behavior, which results in 11 less additional power coming from the fossil heat due to the increase of the steam cycle efficiency. The increase of 12 the steam cycle efficiency can be represented by the boosting factor of steam cycle efficiency:

$$
\Theta_{\text {steam }}=\frac{d \eta_{\text {steam }}}{d Q_{\text {solar }}}
$$

13 The boosting factor of steam cycle efficiency indicates the increase of steam cycle efficiency per unit amount of 14 added solar heat in MWth. Part (b) of Figure 8 compares the solar conversion efficiency and the boosting factor of 15 steam cycle efficiency. As seen in the plot, the solar conversion efficiency has a similar trend as the boosting factor of steam cycle efficiency, which indicates that the former is driven by the latter in this case. 
(a): Comparison of solar conversion efficiency to steam cycle efficiency.

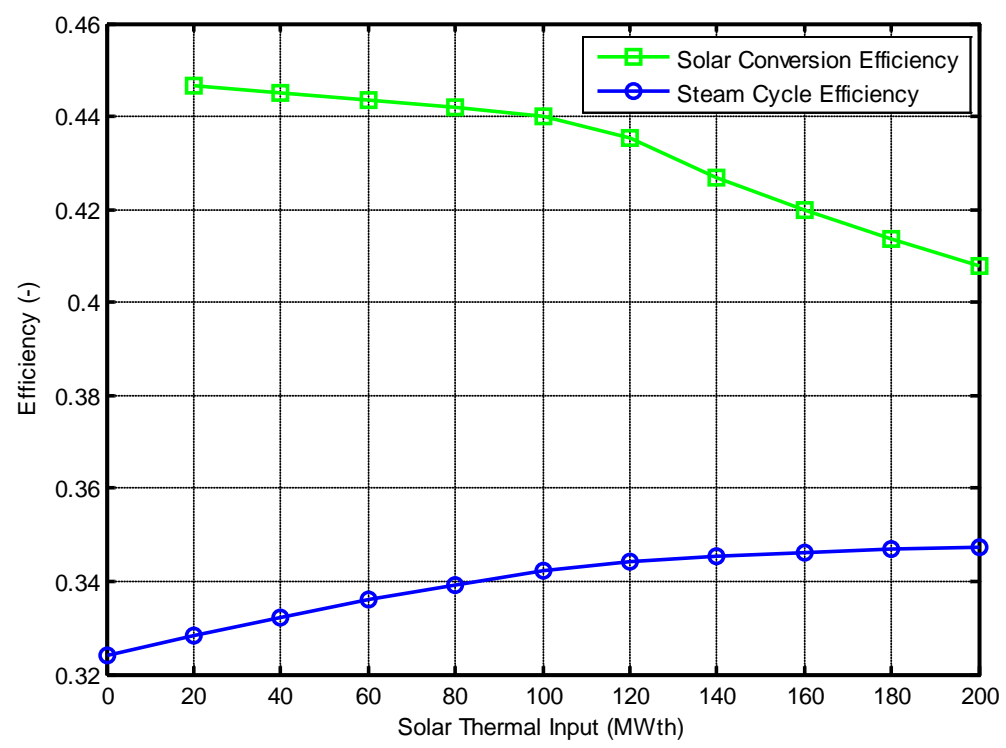

(b): Comparison of solar conversion efficiency to steam cycle efficiency boosting factor.

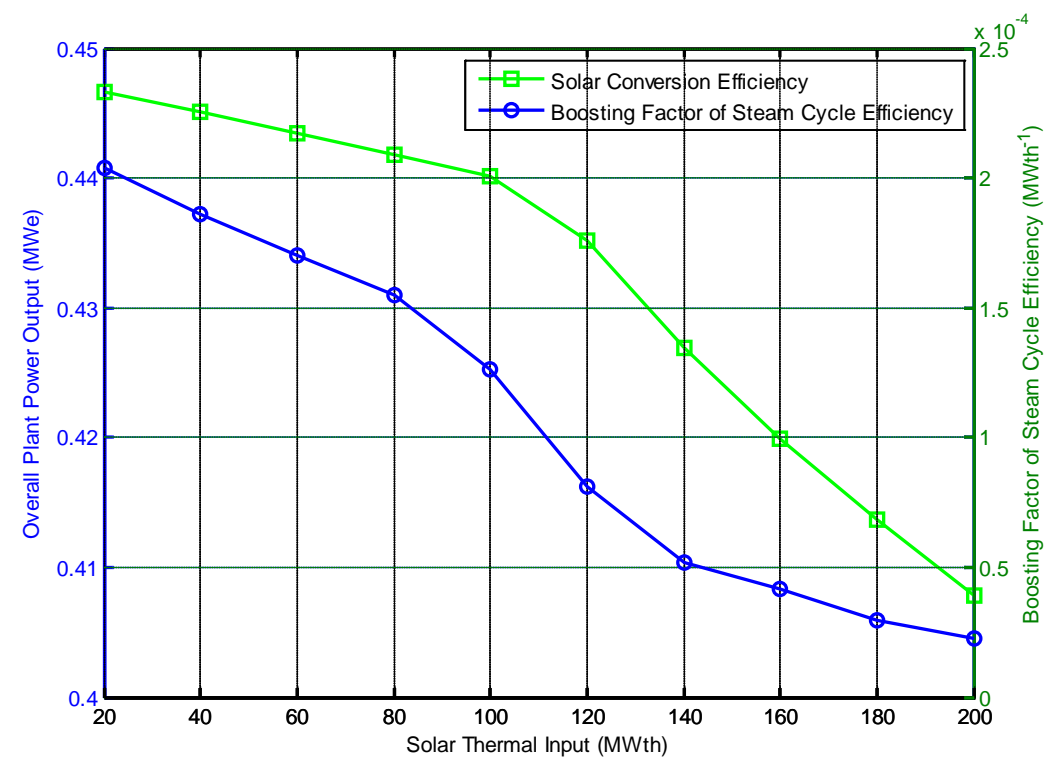

Figure 8: Solar conversion efficiency and steam cycle performance as a function of solar thermal input at an ambient temperature of $20^{\circ} \mathrm{C}$ and a plant elevation of 425 meters.

The overall plant performance is also examined with solar hybridization. Part (a) of Figure 9 shows the overall plant power output and solar fraction as a function of solar thermal input. The overall plant power can be boosted from 475 MWe to about 558 MWe with a solar thermal input of 200 MWth injected to the HRSG. The corresponding solar fraction is about $17 \%$ compared to the overall plant power output. In addition, the overall plant efficiency is plotted in part (b) of Figure 9. Here the calculation of the overall plant efficiency is based on gas consumption alone, that is, solar heat is considered a free heat source. As seen in the figure, the overall plant efficiency is also greatly boosted with the solar addition. At the same time, the increasing solar heat leads to the decreasing HRSG flue gas outlet temperature in most cases, resulting into a slightly increasing HRSG efficiency. 
(a): Overall plant power and solar fraction.

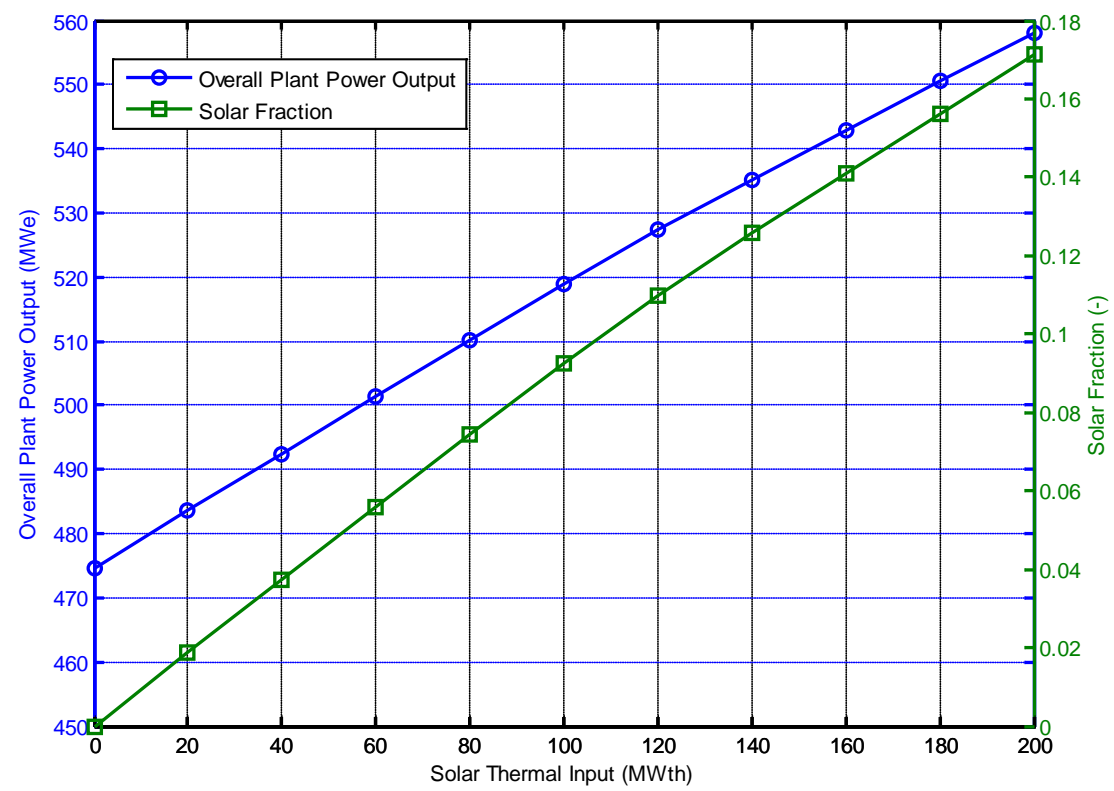

(b): Overall plant efficiency.

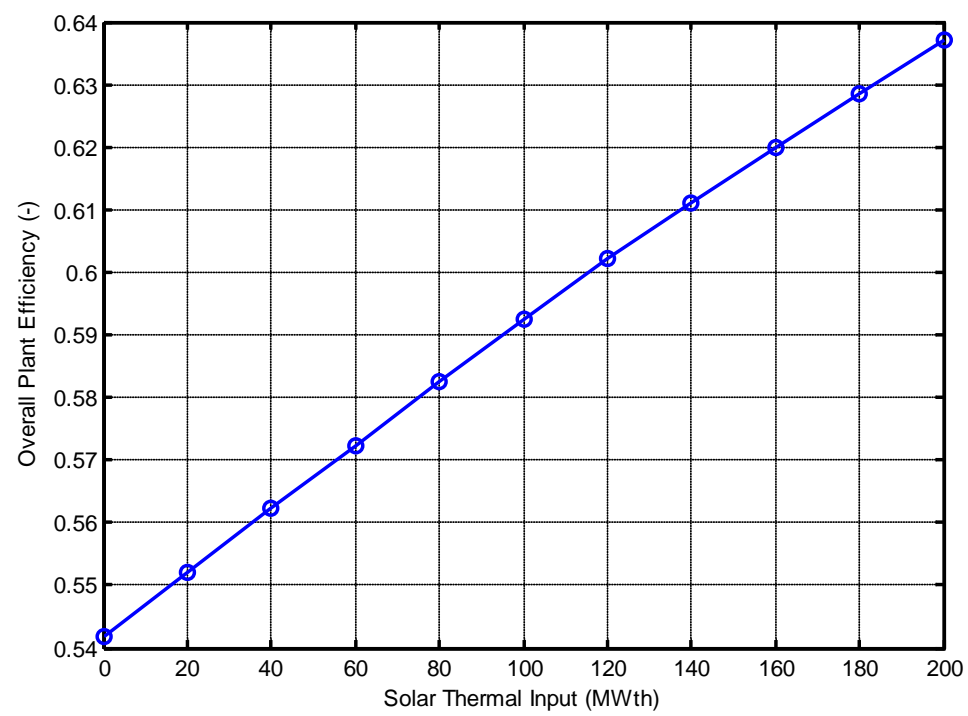

Figure 9: Overall plant performance as a function of solar thermal input at an ambient temperature of $20^{\circ} \mathrm{C}$ and a plant elevation of 425 meters.

7

b. Effect of ambient temperature

Next, the effect of ambient temperature on the ISCC plant is investigated. For a plant located at an elevation of about $425 \mathrm{~m}$, solar conversion efficiency and overall plant power output are plotted as a function of solar thermal input for varying ambient temperature in Figure 10. With increasing solar thermal input, it is noticeable that each 
decreases at a relatively slow rate first and then drops at a relatively fast rate. This fact is closely related to the steam turbine performance with increasing solar heat addition, which is mainly determined by the HP turbine inlet steam temperature under the sliding pressure operation at partial loads. Figure 11 plots the HP turbine inlet steam temperature as a function of the solar thermal input for varying ambient temperatures. It can be seen that, with increasing the steam mass flow rate driven by increasing solar heat, the HP inlet temperature breaks down at some point when the HRSG cannot supply enough superheat to the steam to achieve the desired temperature. The breakdown points for selected ambient temperature in Figure 11 matches the rate-change points in Figure 10.

8

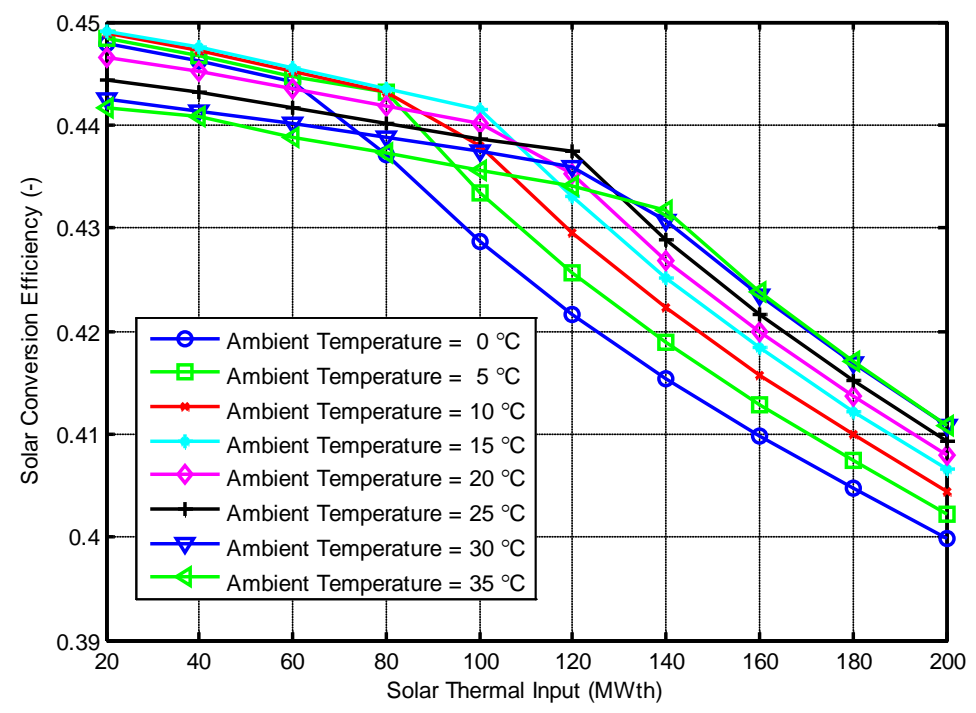

Figure 10: Solar conversion efficiency as a function of solar thermal input for varying ambient temperature at a plant elevation of 425 meters.

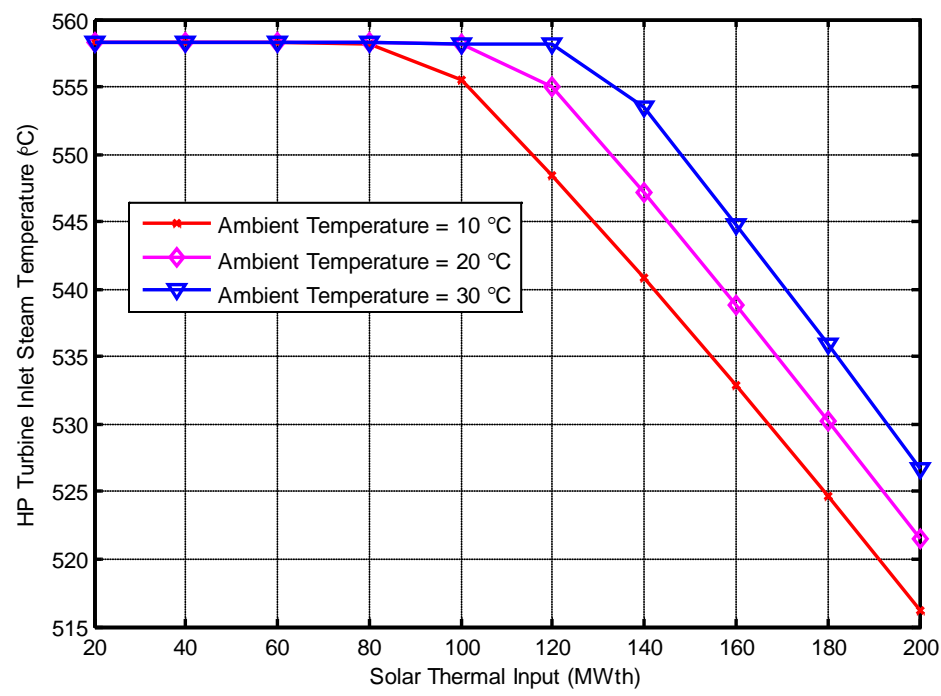

Figure 11: HP turbine inlet steam temperature as a function of solar thermal input for varying ambient temperature at a plant elevation of 425 meters. 
1 Another noticeable fact in Figure 10 is that the solar conversion efficiency curves for different ambient temperatures 2 cross each other with increasing solar heat. At relatively low solar heat input, the solar conversion efficiency is 3 higher at low ambient temperatures in general, and then becomes lower at high ambient temperatures. It is known 4 that solar conversion efficiency depends on two things: the boosted power out of solar heat and the power boosted 5 from the fossil heat due to the improvement of steam cycle efficiency. The former is determined by the steam cycle 6 efficiency and the latter is determined by the boosting factor of the steam cycle efficiency $\left(\Theta_{\text {steam }}\right.$, as in equation 7 (4)). Both are plotted for varying ambient temperature in Figure 12. The steam cycle efficiency increases with 8 increasing solar heat as shown in Figure 12(a) and its boosting factor decreases instead in Figure 12(b). However, 9 with the increasing ambient temperature, the former decreases and the latter increases. Combining with the trend of 10 solar conversion efficiency in Figure 10, it can be seen that the response of the solar conversion efficiency is the 11 interplay of the steam cycle efficiency and its boosting factor. Generally speaking, the solar conversion efficiency is 12 higher at lower ambient temperatures when the solar heat is small and higher at higher ambient temperature when 13 the solar heat is large. For a typical day, the DNI (which corresponds to solar heat) typically increases with 14 increasing ambient temperature, thus the solar hybridization could serve as a natural means to smooth the plant 15 power output if carefully designed. 
(a): Steam cycle efficiency.

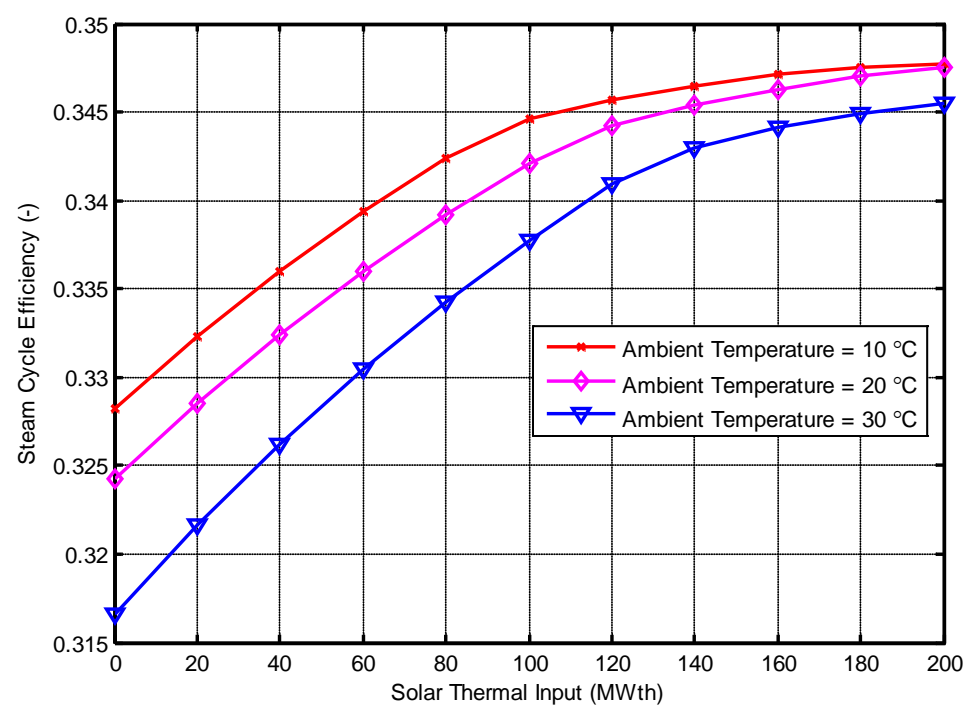

2

(b): Boosting factor of steam cycle efficiency.

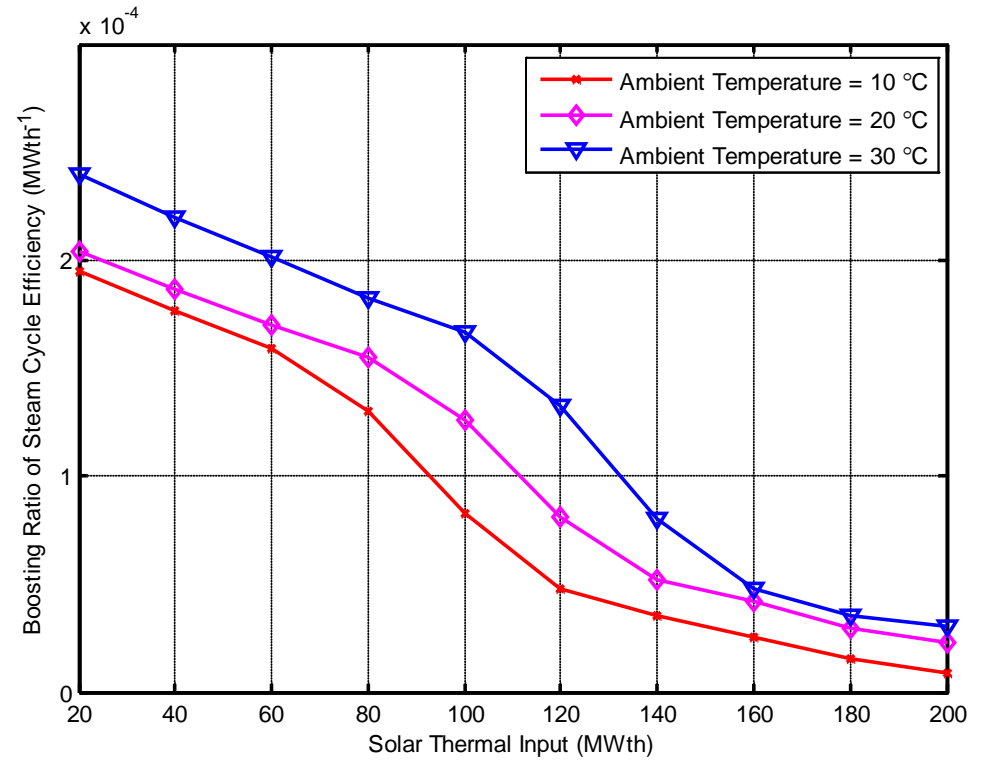

Figure 12: Thermodynamic response of steam cycle as a function of solar thermal input for varying ambient temperature at a plant elevation of 425 meters.

The impact of ambient temperature to the overall plant power output is also plotted as in Figure 13. The overall plant power output consistently increases with decreasing ambient temperature as shown. For a typical NGCC plant without solar, the performance of both the gas turbine and the steam turbine condenser is sensitive to the ambient temperature so that the overall plant power output is affected accordingly as a consequence. 


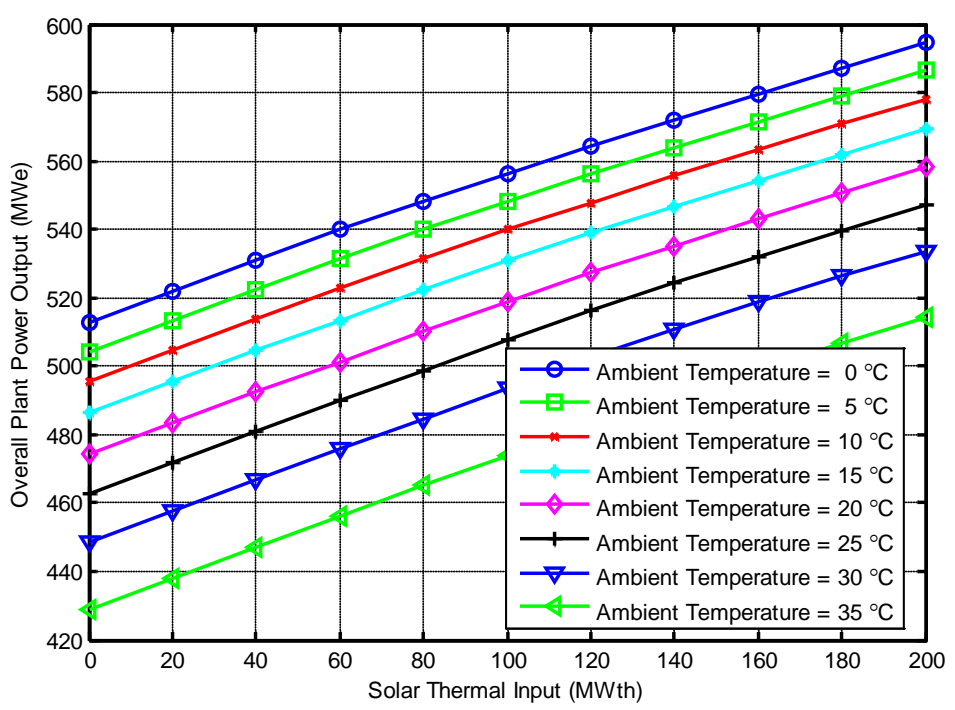

Figure 13: Overall plant power output as a function of solar thermal input for varying ambient temperature at a plant elevation of 425 meters.

\section{V. Conclusions and Future Work}

The work here utilizes a sophisticated physical model of an ISCC plant to investigate the system response to different levels of solar hybridization. The ISCC model is able to accurately capture off-design performance and allows the evaluation of solar hybridization from a thermodynamic perspective for a wide range of input parameters. The modeling results show that solar hybridization into an NGCC plant may achieve a solar conversion efficiency greater than steam cycle efficiency for cases where the steam turbine cycle is oversized to accommodate duct burners. Due to the varying ambient conditions, the NGCC often runs at lower cycle efficiency under partial loads without using duct burners. Solar addition into the NGCC HRSG not only boosts the plant power output but also the bottom cycle efficiency, thus resulting in high solar conversion efficiency. In addition, using solar power to replace partial load of a high-capacity HP evaporator in the HRSG may also provide a significant solar fraction up to about $17-20 \%$, which leads to a substantial saving of fossil-fuel and a corresponding reduction in greenhouse-gas emissions.

The benefits of solar hybridization may depend on plant elevation. The plant elevation is closely correlated with the ambient pressure. The change in ambient pressure has a significant impact on the gas turbine performance, and thus the HRSG and steam turbine. It also affects the performance of the condensing system. Overall, its impact on an NGCC plant is substantial and thus an NGCC plant is typically required to be carefully redesigned for a specific plant elevation. However, the impact of ambient pressure to the solar hybridization is minimal, based on the preliminary results. The solar conversion efficiency may still be well beyond the steam turbine cycle efficiency, still higher than $40 \%$, when the plant elevation changes.

These modeling results may also naturally serve as a basis to evaluate the annual performance of an ISCC plant. An annual ISCC model as part of NREL's System Advisor Model (SAM) [17] is under development. The annual ISCC model will be able to perform annual simulations with realistic weather data and integrate SAM's financial models to calculate the economic metrics of an ISCC system such as the internal rate of return (IRR) and levelized cost of energy (LCOE). One may also choose different solar field technologies with various design parameters. The annual ISCC model in SAM will provide a valuable reference to researchers and interested industries on the evaluation of ISCC systems. 


\section{VI. Acknowledgements}

2

\section{VII. References} p. 32-35.

The work at NREL was supported by the U.S. Department of Energy under Contract No. DE-AC36-08-GO28308. The authors wish to thank Robin Bedilion and Cara Libby from EPRI for their kindest support on the original ISCC model. The authors greatly benefitted from discussions with June Chen at GE Global Research. Special thanks go to Mike Erbes at Enginomix for his support on the IPSEpro modeling.

1. Kearney, D. and F. Morse, Bold, Decisive Times for Concentrating Solar Power. Solar Today, 2010. 24(4):

2. $\quad$ SunShot Vision Study, 2012, U.S. Department of Energy: Washington D.C.,.

3. CSP World. Available from: http://www.csp-world.com/cspworldmap.

4. $\quad$ Renewable 2011 Global Status Report, L. Mastny, Editor 2011, REN21: Paris, France, .

5. Sheu, E., et al., A Review of Hybrid Solar-Fossil Fuel Power Generation Systems and Performance Metrics. the ASME Journal of Solar Energy Engineering, 2012. 134.

6. $\quad$ the NREL concentrating solar power program. Available from: www.nrel.gov/csp.

7. Kelly, B., U. Herrmann, and M.J. Hale. Optimization studies for integrated solar combined cycles. in Proceedings of Solar Forum 2001. 2001. Washington DC.

8. Dersch, J., et al., Trough integration into power plants-a study on the performance and economy of integrated solar combined cycle systems. Energy, 2004. 29: p. 947-959.

9. McMahan, A. and N. Zervos, Integrating Steam Generation from Concentrating Solar Thermal Collectors to Displace Duct Burner Fuel in Combined Cycle Power Plants, in Power-Gen International 20092009: Las Vegas.

10. Ojo, C.O., et al., Performance Evaluation of an Integrated Solar Combined Cycle, in 2012 ASME TurboExpo2012: Copenhagen, Denmark.

11. Montes, M.J., et al., Performance analysis of an Integrated Solar Combined Cycle using Direct Steam Generation in parabolic trough collectors. Applied Energy, 2011. 88(9): p. 3228-3238.

12. Libby, C. and e. al., Solar Augment Steam Cycles for Natural Gas Plants: Conceptual Design Study, 2009, Electric Power Research Institute.

13. Libby, C. and e. al., Solar Augmented Steam Cycles for Natural Gas Plants: Chuck Lenzie Generating Station Development Guideline Manual, 2010, Electric Power Research Institute.

14. Manzolini, G., et al., Development of an Innovative Code for the Design of Thermodynamic Solar Power Plants Part B: Performance Assessment of Commercial and Innovative Technologies. Renewable Energy, 2011. 36: p. 2465-2473.

15. El Hadik, A.A., The Impact of Atmospheric Conditions on Gas Turbine Performance. Journal of Engineering for Gas Turbine Power, 1990. 112(4): p. 590-596.

16. Turchi, C. and Z. Ma, Gas Turbine/Solar Parabolic Trough Hybrid Design Using Molten Salt heat Transfer Fluid, in 2011 SolarPACES2011: Granada, Spain.

17. NREL. System Advisor Model. Available from: https://sam.nrel.gov/. 